\title{
Carbon Monoxide Oxidation under Transient Conditions: A Fourier-Transform Infrared Transmission Spectroscopy Study
}

\author{
Yoav Barshad, Xiaochuan Zhou, and Erdogan Gulari ${ }^{1}$ \\ Department of Chemical Engineering, University of Michigan, Ann Arbor, Michigan 48109
}

Received September 19, 1984; revised February 5, 1985

\begin{abstract}
In contrast to the apparent simplicity of the overall reaction, oxidation of $\mathrm{CO}$ over $\mathrm{Pt} / \mathrm{A}_{2} \mathrm{O}_{3}$ is known to present complex behavior. Self-sustained oscillations, hysteresis loops in conversion, and enormous rate enhancements under forced feed concentration cycling have been observed. In this study the dynamic behavior of the IR-active surface $\mathrm{CO}$ species was followed with a fast-scan Fourier-Transform Infrared (FTIR) during transient response and periodic operation. Depending on the conditions, up to four linearly adsorbed CO bands at 2123,2092, 2073, and $2061 \mathrm{~cm}^{-1}$, and a bridge-bonded $\mathrm{CO}$ band at $1850 \mathrm{~cm}^{-1}$ were observed. The time-averaged and transient intensities of the bands were found to be significantly different during periodic operation as comparcd to stcady state. Linearly adsorbed $\mathrm{CO}$ on metallic platinum $\left(2073 \mathrm{~cm}^{-1}\right)$ was found to have the fastest response to changes in the gas-phase concentration. It was also observed that $\mathrm{CO}$ adsorbed on platinum oxide is very stable and does not take part in the reaction to any appreciable extent. $\mathrm{CO}_{2}$ production rates during periodic operation were found to correlate extremely well with the integrated total absorbance of the 2092- $\mathrm{cm}^{-1}$ band, assigned to $\mathrm{CO}$ linearly adsorbed on a platinum atom sharing an oxygen with a neighbor. Based on the experimental observations a detailed mechanism of $\mathrm{CO}$ oxidation on platinum is proposed. The model can successfully explain the enormous rate enhancements observed during periodic operation. (c) 1985 Academic Press, Inc.
\end{abstract}

\section{INTRODUCTION}

Oxidation of $\mathrm{CO}$ over supported platinum exhibits a number of complex behavior patterns under a variety of reaction conditions. Self-sustained oscillations of reaction rate under steady feed stream concentrations were initially observed by Hugo and Jakubith (1). The interest in this phenomenon grew rapidly and the subject was reviewed by Schmitz (2) and by Slinko (3). Hysteresis loops, where more than one steady state are observed depending on the history of the reactor's environment in terms of temperature or inlet concentration of $\mathrm{CO}$, are well documented $(4,5)$. Cutlip (6) found that the (time average) rate of reaction under isothermal conditions could be enhanced dramatically (more than an order of magnitude compared to the equivalent steady state) by periodically switching the feed between $\mathrm{CO}$ and $\mathrm{O}_{2}$. This work by

${ }^{1}$ To whom correspondence should be addressed.
Cutlip has been extended to shorter switching periods by Barshad and Gulari (7), where the switching times were short enough to be comparable to the surface processes. An extensive mapping of this phenomenon, with respect to the parameters associated with periodic operation, was also presented.

This complex behavior stands in sharp contrast with the apparent simplicity of the reaction if the gas-phase species alone are considered. Efforts to model this reaction, by accounting for surface reaction with bimolecular Langmuir-Hinshelwood (LH) rate expression, have resulted in limited success. Rate expressions that are based on the assumption that both $\mathrm{CO}$ and $\mathrm{O}_{2}$ adsorption processes are in equilibrium can hardly predict the steady-state rate of reaction over a limited range of pressures and concentrations. Herz and Marin (8) developed a model which describes the experimental behavior of $\mathrm{CO}$ oxidation without invoking the competitive equilibrium ad- 
sorption assumption of $\mathrm{CO}$ and $\mathrm{O}_{2}$ that is often used in conjunction with the LH mechanism. Even with the more sophisticated models, it is impossible to predict the complex behavior mentioned above. Therefore, it is quite clear that the complexity is introduced by the number of surface species of both $\mathrm{CO}$ and oxygen, the interaction of which, with the catalysts and with each other, is not yet clear.

Infrared spectroscopy is one of the few techniques that can be used for in situ experiments at atmospheric pressure. Especially attractive, in this case, is the fact that $\mathrm{CO}$ adsorbed on $\mathrm{Pt} / \mathrm{Al}_{2} \mathrm{O}_{3}$ has intense absorption bands in the IR spectra. The availability of a large amount of IR data for this system is also helpful in interpreting the results.

The purpose of this study was to investigate the transients of surface $\mathrm{CO}$ species in all the IR absorption bands. The experiments were designed to follow the rate of adsorption on reduced and oxidized platinum and to explore the behavior of surface species under periodic operation where significant rate enhancement is observed. Specifically, the answers to the following questions were sought:

1. Can transients in any of the surface species be correlated with the transients in $\mathrm{CO}_{2}$ production (dynamic and time average)?

2. What is the dynamic behavior of surface $\mathrm{CO}$ species under reactive and nonreactive conditions?

3 . What is the role of platinum and platinum oxide in the reaction?

4. To what extent can rate enhancements be attributed to temperature excursions on the catalyst surface?

\section{EXPERIMENTAL}

\section{a. Catalyst and Reagents}

A $6.2 \mathrm{wt} \% \mathrm{Pt} / \mathrm{Al}_{2} \mathrm{O}_{3}$ was prepared by impregnating high-purity alumina (BDH) with aqueous $\mathrm{H}_{2} \mathrm{PtCl}_{6}$ solution. The catalyst was then dried in air for $2 \mathrm{~h}$ and calcined in air at $773 \mathrm{~K}$ for $4 \mathrm{~h}$. The catalyst powder was pressed into pellets by a 25.4-mm die using $80 \mathrm{mg}$ per pellet. The resulting pellet thickness was $0.25 \mathrm{~mm}$. Dispersion was found to be $16 \%$ using $\mathrm{CO}$ and $\mathrm{O}_{2}$ chemisorption at room temperature. Before using, the catalyst was pretreated in situ by flowing $\mathrm{O}_{2}$ and then $\mathrm{H}_{2}$ for $2 \mathrm{~h}$ at atmospheric pressure and $503 \mathrm{~K}$.

The gases used were $99.99 \%$ pure $\mathrm{N}_{2}$ (Air Products), 99.99\% pure $\mathrm{O}_{2}$ (Matheson), and 99.6\% pure $\mathrm{CO}$ containing $0.3 \% \mathrm{~N}_{2}$, traces of $\mathrm{Ar}$ and $\mathrm{CO}_{2}$, and $20 \mathrm{ppm}$ of $\mathrm{Fe}(\mathrm{CO})_{5}$. Iron carbonyl was removed by decomposing it at $700 \mathrm{~K}$. The results were found to be identical with or without the carbonyl trap.

\section{b. Apparatus}

Details of the flow measurement and control system are given elsewhere (9). The system is capable of switching the feed to the single-pellet reactor between different streams with different compositions of $\mathrm{CO}$, $\mathrm{O}_{2}$, and $\mathrm{N}_{2}$ without changing the total volumetric flow rate, thus keeping the residence time constant to $\pm 2 \%$.

The catalyst pellet was mounted in a liquid IR cell (Harrick) with $25.4-\mathrm{mm} \mathrm{NaCl}$ windows and an optical path length of 0.9 $\mathrm{mm}$. This short path length eliminated the IR signal from gas-phase $\mathrm{CO}$. The cell was heated by a heating tape and the temperature was controlled to $\pm 0.5 \mathrm{~K}$.

\section{c. Procedure}

The majority of the experimental work presented here was performed with the sample at $413 \mathrm{~K}$, and a total pressure of $104.2 \mathrm{kPa}$. The flow rate through the sample cell was $85 \mathrm{~cm}^{3} / \mathrm{min}$, which along with a cell volume of $1 \mathrm{~cm}^{3}$ resulted in a residence time of $<1 \mathrm{sec}$. Since the shortest cycle time used in this study was $10 \mathrm{sec}$, the shape of the transients is not significantly distorted by the filtering action of the cell.

Two different kinds of experiments are presented in this paper. The first is the transient response of surface species to a step change in gas-phase composition of the feed. The second kind is periodic operation 
where the reactor inlet was switched between 15 vol\% $\mathrm{O}_{2}$ in $\mathrm{N}_{2}$ and 10 vol\% $\mathrm{CO}$ in $\mathbf{N}_{2}$. There are two parameters associated with this type of operation that are worth defining: (i) time period (TP), as in any other cyclic process, is the time it takes the process to repeat itself; and (ii) duty fraction (DF) is the fraction of the time period that $\mathrm{CO}$ is in the feed stream. The results that we present in this paper correspond to a duty fraction of 0.2 (for reasons that will be discussed later). The time-averaged concentrations were used as a reference for periodic operation.

All the IR spectra were taken with a fastscan Digilab FTS-20 Fourier-transform IR spectrometer capable of taking up to seven spectra/second with a resolution of $8 \mathrm{~cm}^{-1}$. For most of the data presented here the actual time resolution was $0.6 \mathrm{sec}$ since an interactive data acquisition program was used.

Time-averaged spectra were also taken in both periodic operation and steady-state experiments. In those cases a higher resolution of $4 \mathrm{~cm}^{-1}$ was used and speed was of no interest. Once repetitive steady operation was achieved, successive spectra were averaged over 10 time periods to determine the time-averaged surface coverage, with high signal-to-noise ratio.

\section{RESULTS}

The main features of our steady state and transient spectra are the four bands shown in Fig. 1. These four bands exist with different intensities under all of our operating conditions. The first is an intense band at $2120 \mathrm{~cm}^{-1}$, the frequency of which varied between 2123 and $2119 \mathrm{~cm}^{-1}$. This band, according to traditional assignment, is due to carbon monoxide adsorbed on supported platinum oxide (10). The second is the $2092-\mathrm{cm}^{-1}$ band that sometimes looked like a shoulder on the 2120 - or the $2073-\mathrm{cm}^{-1}$ bands, but in other cases was distinct and clear with some structure consisting of peaks at 2090 and $2094 \mathrm{~cm}^{-1}$. This band is assigned to $\mathrm{CO}$ adsorbed on a platinum

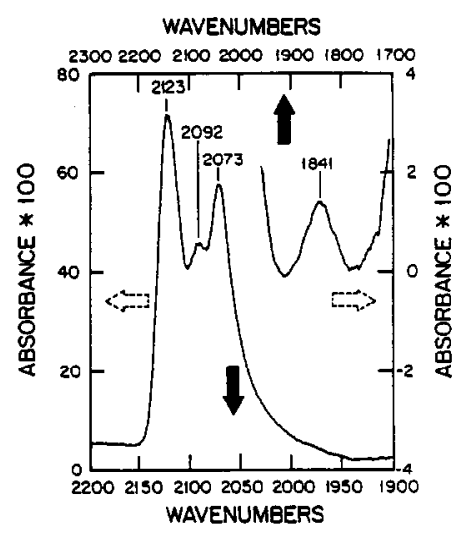

FIG. 1. The four CO IR bands that were followed in this investigation.

atom sharing an oxygen with a coordination number of about $+1(10)$. The third, and the last in this group of bands, due to linearly adsorbed $\mathrm{CO}$, is the $2073-\mathrm{cm}^{-1}$ band, assigned to $\mathrm{CO}$ adsorbed on reduced platinum crystallites (10). This band was also strong and distinct and was located between 2073 and $2080 \mathrm{~cm}^{-1}$ under reactive conditions. The fourth band located at $1850 \mathrm{~cm}^{-1}$ is due to bridge-bonded $\mathrm{CO}$. This band was relatively weak, 0.01-0.02 adsorbance units compared to 30 to 100 absorbance units for the 2073- $\mathrm{cm}^{-1}$ band, and did not change its frequency. A fifth band at $\sim 2060 \mathrm{~cm}^{-1}$ was observable at times as a distinct band during $\mathrm{CO}$ adsorption transients on reduced $\mathrm{Pt}$ and as a shoulder during periodic operation. This band is assigned to CO linearly adsorbed on $\mathrm{Pt}$ atms with low coordination numbers.

\section{a. Effect of Hydrogen on the $\mathrm{CO}$ Spectrum}

Figure 2 shows the $\mathrm{CO}$ adsorption spectrum after first exposing the catalyst to the reaction mixture for $24 \mathrm{~h}$ and then switching the feed to $15 \% \mathrm{H}_{2}$ in $\mathrm{N}_{2}$ in $\mathrm{N}_{2}$ at $413 \mathrm{~K}$ for $30 \mathrm{~min}$. The important points to note are that the intensity of the $2120-\mathrm{cm}^{-1}$ band is very small, the $2073-\mathrm{cm}^{-1}$ band is shifted down in frequency to $2063 \mathrm{~cm}^{-1}$, there are low-frequency shoulders at 2031 and 1980 $\mathrm{cm}^{-1}$, and that the total integrated intensity 


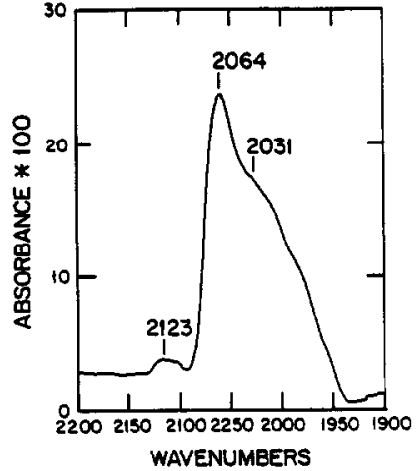

FIG. 2. IR spectrum of adsorbed CO obtained after reducing a broken-in catalyst with hydrogen for $\mathbf{3 0}$ min.

is only about one-third of that shown in Fig. 1.

\section{b. CO Adsorption on Reduced Catalyst}

Figures $3 a$ and $b$ present the dynamics of $\mathrm{CO}$ adsorption on reduced platinum. After aging and reducing the catalyst the cell was

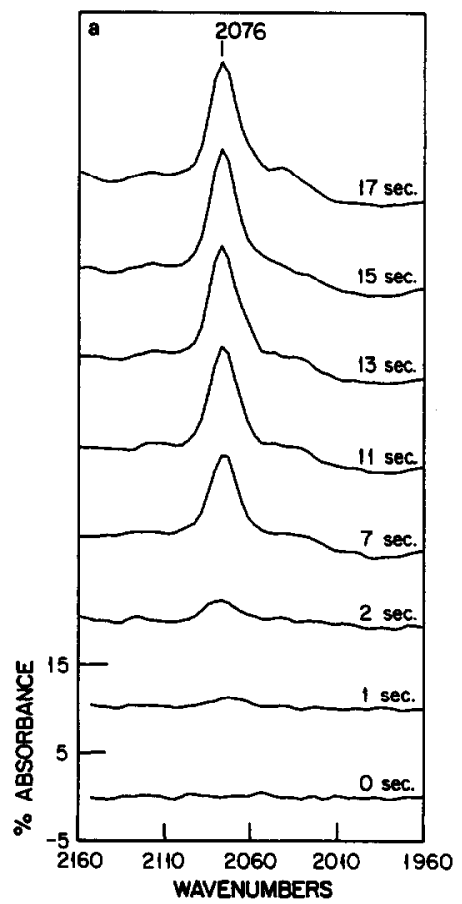

purged with nitrogen, and at time zero the feed was switched to $10 \% \mathrm{CO}$ in $\mathrm{N}_{2}$ and successive spectra averaged over $1 \mathrm{sec}$ each were taken. We see that from time zero to $17 \mathrm{sec}$ the frequency of the main peak is constant at $2076 \mathrm{~cm}^{-1}$. After $7 \mathrm{sec}$ a low-frequency shoulder at approximately $2044 \mathrm{~cm}^{-1}$ becomes visible. The main peak is due to $\mathrm{CO}$ linearly adsorbed on $\mathrm{Pt}^{\mathrm{t}}$, and the wide shoulder is probably due to adsorption on low-coordination sites. The changes in the $1850-\mathrm{cm}^{-1}$ bridge-bonded $\mathrm{CO}$ band were much slower and, because of lower $\mathrm{S} / \mathrm{N}$, were not analyzed. Following the increases in the height of the $2076-\mathrm{cm}^{-1}$ band revealed that there were two time constants, a short one of $\sim 3 \mathrm{sec}$ and a much longer one of $\sim 30 \mathrm{sec}$. Exposure to $\mathrm{CO}$ for 15 min produces dramatic changes in the band shapes: the peak absorbance is double that of $t=17 \mathrm{sec}$, the peak frequency shifts down to $2073 \mathrm{~cm}^{-1}$, and the low-frequency side is very asymmetric.

Oxidation of $\mathrm{CO}$ adsorbed on to the catalyst by first purging the gas-phase $\mathrm{CO}$ and

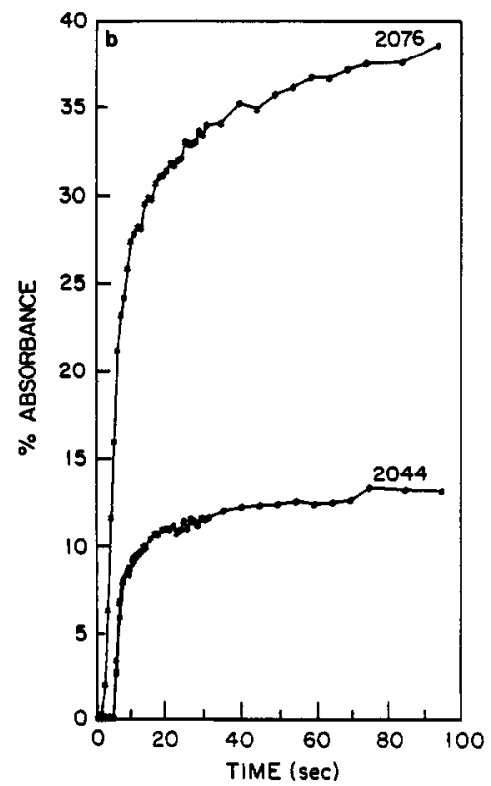

Fig. 3. (a) Time-dependent $\mathrm{CO}$ adsorption spectra on the reduced catalyst. Only some of the representative individual spectra are shown. (b) Peak absorbance at $2076 \mathrm{~cm}^{-1}$ measured as a function of time. Also shown is the time-dependent absorbance of the shoulder at $2044 \mathrm{~cm}^{-1}$. Absorbances shown in this figure were obtained from individual spectra, some of which are shown in (a). 
then switching the feed to $10 \% \mathrm{O}_{2}$ in $\mathrm{N}_{2}$ showed no unusual transients. The intensity of the 2073- $\mathrm{cm}^{-1}$ band decreased uniformly without showing any shifts in frequency.

Figure 4 shows the dynamics of $\mathrm{CO}$ adsorption onto partially oxidized catalyst. The catalyst was pretreated with oxygen for $30 \mathrm{~min}$ and then the gas-phase $\mathrm{O}_{2}$ was flushed with $\mathrm{N}_{2}$ before introducing $10 \% \mathrm{CO}$ in $\mathrm{N}_{2}$. The frequency of the band assigned to $\mathrm{CO}$ adsorbed on platinum oxide stays constant at $2122 \mathrm{~cm}^{-1}$ whereas the frequency of the more intense band at 2087 $\mathrm{cm}^{-1}$ slowly shifts down to $2076 \mathrm{~cm}^{-1}$ after $20 \mathrm{sec}$ and all the way down to $2073 \mathrm{~cm}^{-1}$ after $10 \mathrm{~min}$.

\section{c. Periodic Operation Results}

All the periodic operation experiments and the equivalent steady-state experiments were carried out with the same timeaverage concentration of both $\mathrm{CO}$ and $\mathrm{O}_{2}$. In order to keep the number of variables to

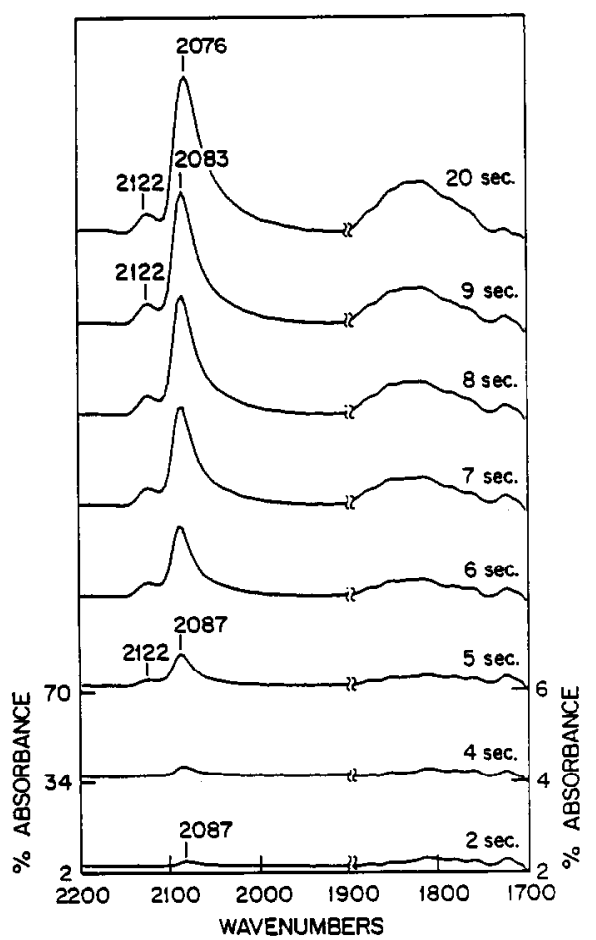

FIG. 4. Time-dependent $\mathrm{CO}$ adsorption spectra on partially oxidized catalyst. a minimum $\mathrm{CO}\left(10 \% \mathrm{CO}\right.$ in $\left.\mathrm{N}_{2}\right)$ was fed into the reactor $20 \%$ of the time (duty fraction of 0.2 ) while oxygen was flowing in for the rest of the time. The period of cycling was varied from 10 to $50 \mathrm{sec}$. The equivalent steady-state feed concentrations corresponding to this cyclic feed strategy are $2 \%$ $\mathrm{CO}, 12 \% \mathrm{O}_{2}$, and $86 \% \mathrm{~N}_{2}$.

The reactor reaches steady cyclic operation fairly quickly, a fact that was verified by comparing spectra averaged over 5 periods and spaced 15-20 min apart. When the difference between two such spectra diminished to the noise level (0.002 absorbance units) it was considered to be steady periodic operation.

Figure 5 shows the time-averaged spectra obtained by adding and averaging 400 to 800 successive scans spanning exactly a whole number of time periods. The spectra in Fig. 5 can be divided, qualitatively, into two groups. Steady state, $10-$, and 20 -sec time periods show high absorbance at $2077 \mathrm{~cm}^{-1}$ and relatively low absorbance at $2123 \mathrm{~cm}^{-1}$. $\mathrm{TP}=30-, 40-$, and 50-sec spectra have higher absorbances at $2123 \mathrm{~cm}^{-1}$, a new band at $2092 \mathrm{~cm}^{-1}$, and much lower absorbance at $2073 \mathrm{~cm}^{-1}$.

Proceeding on the assumption that the spectra in Fig. 5a are the result of superposition of several individual peaks with Gaussian lineshapes, we have deconvoluted the spectra to quantitate the contribution of each surface $\mathrm{CO}$ species. The results of the deconvolution are summarized in $\mathrm{Ta}$ ble 1. Important points to note are that the total integrated absorbance is approximately constant, the half-widths of the 2123- and $2073-\mathrm{cm}^{-1}$ bands are relatively constant whereas the half-width of the $2092-\mathrm{cm}^{-1}$ band increases fivefold. Simultaneous with these measurements the timeaveraged rate of $\mathrm{CO}_{2}$ concentration in the outlet was measured with an external IR detector. The correlation between the timeaveraged spectra and the $\mathrm{CO}_{2}$ production rate is shown in Fig. $5 \mathrm{~b}$ where the changes from the steady state are plotted. The most important observation to be made in Fig. 5b 

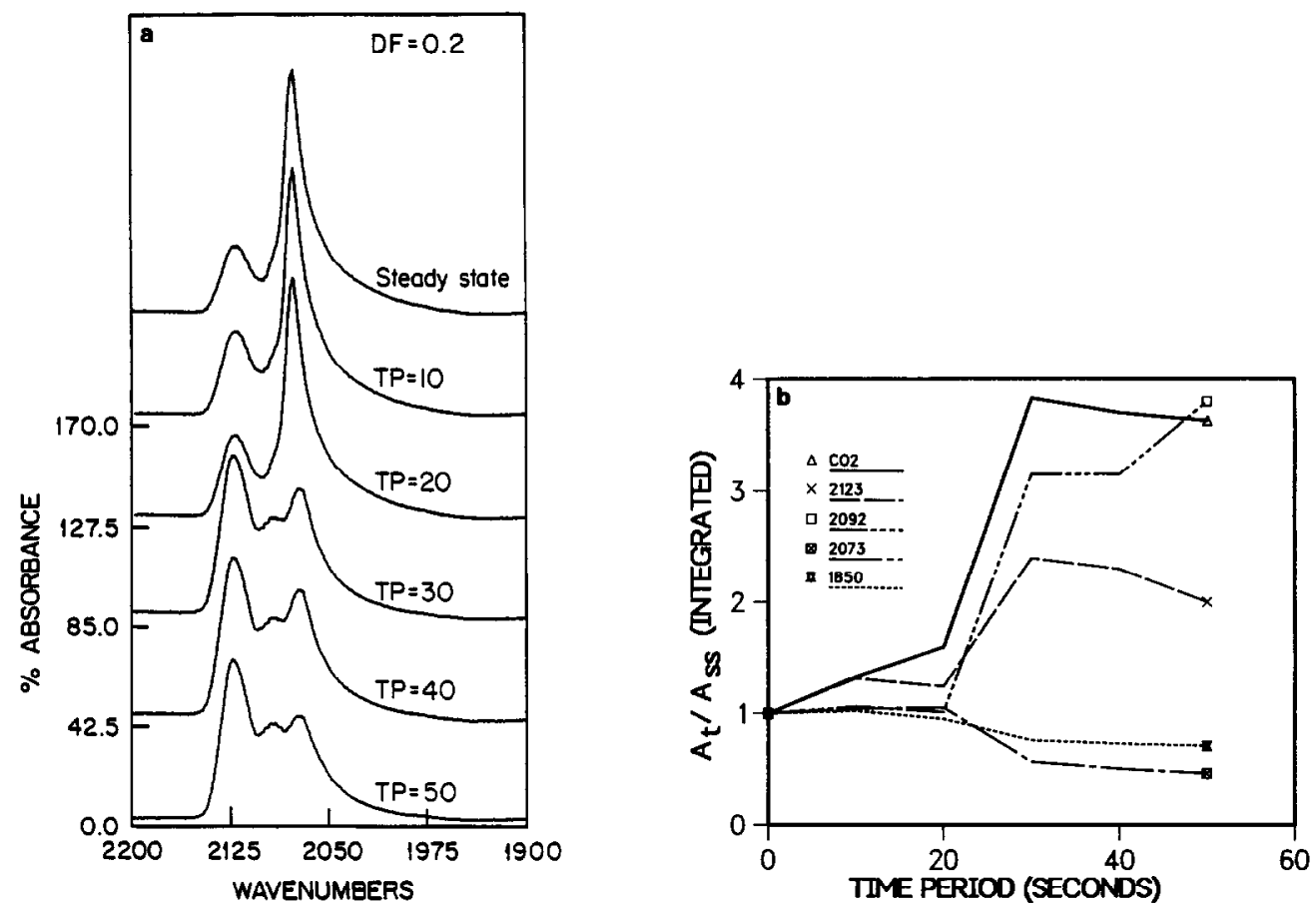

FIG. 5. (a) Time-averaged IR spectra under steady state and periodic operation. The steady-state feed is $2 \% \mathrm{CO}$ and $12 \% \mathrm{O}_{2}$ the rest being $\mathrm{N}_{2}$. Periodic operation consisted of switching between $10 \%$ $\mathrm{CO}$ and $15 \% \mathrm{O}_{2}$ with a $\mathrm{CO}$ duty fraction of 0.2 , resulting in exactly the same time-averaged gas-phase composition as the steady state. (b) Plot of the integrated peak areas for the various CO bands during periodic operation ratioed to their steady-state values. Also shown is the ratio of the time-averaged $\mathrm{CO}_{2}$ production rate. The curve shown for the $1850-\mathrm{cm}^{-1}$ band is a ratio of the peak heights and not the integrated peak areas.

is that the 2123- and 2092- $\mathrm{cm}^{-1}$ bands have positive correlation and the $2073-\mathrm{cm}^{-1}$ band has negative correlation with the changes in the $\mathrm{CO}_{2}$ concentration.

While the time-averaged spectra during periodic operation are helpful in determining what changes are taking place on the catalyst surface they do not have the time resolution to answer questions about the reaction intermediates. In order to address the question of the species responsible for the increased $\mathrm{CO}_{2}$ production 0.6-sec time resolution IR spectra was taken during periodic operation. The data was analyzed in two ways, by simultaneously following the absorbance at the fixed wavenumbers of 2123, 2092, 2073, and $1850 \mathrm{~cm}^{-1}$ with a bandwidth of 8 wavenumbers, and by deconvoluting the individual spectra as a sum of Gaussians. Figure 6a shows the results of the first type of analysis. Figures $6 \mathrm{~b}$ and $c$ show individual spectra taken at the certain points shown in Fig. 6a. Important points to note in Fig. $6 \mathrm{a}$ are: the absorbances at 1850 and $2123 \mathrm{~cm}^{-1}$ change very little with the changes in the gas-phase composition, 2073and $2092-\mathrm{cm}^{-1}$ absorbances change significantly during one cycle, and that there is a 20 -sec induction time (the distance $A$ in the figure) after oxygen is turned on before any significant changes are seen in the absorbances. This induction time was found to be a strong function of temperature.

Table 2 gives the results of the Gaussian deconvolution by nonlinear least-squares analysis. Overall the quality of the fits were very good (correlation coefficients $\geq 0.9999$ or an average deviation of less than $0.5 \%$ between the fitted and the experimental curve). In this analysis inclusion of a fourth 


\section{TABLE 1}

Deconvolution of Time-Averaged IR Absorption Spectra of CO Obtained during Periodic Operation into Individual Pcaks

\begin{tabular}{|c|c|c|c|c|c|}
\hline & \multicolumn{5}{|c|}{ Time period (sec) } \\
\hline & S.S. & 10 & 20 & 30 & 40 \\
\hline Frequency, $\mathrm{cm}^{-1}$ & 2120 & 2120 & 2122 & 2124 & 2124 \\
\hline Peak height & 25 & 31 & 32 & 57 & 56 \\
\hline Half-width, $\mathrm{cm}^{-1}$ & 8.5 & 9.0 & 8.4 & 9.1 & 9.1 \\
\hline Integrated area & 539 & 707 & 670 & 1295 & 1269 \\
\hline Frequency, $\mathrm{cm}^{-1}$ & 2092 & 2092 & 2092 & 2092 & 2092 \\
\hline Peak height & 32 & 32 & 33 & 21 & 21 \\
\hline Half-width, $\mathrm{cm}^{-1}$ & 5.8 & 5.9 & 5.6 & 26 & 26 \\
\hline Integrated area & 457 & 487 & 461 & 1362 & 1362 \\
\hline Frequency, $\mathbf{c m}^{-1}$ & 2077 & 2077 & 2077 & 2073 & 2073 \\
\hline Peak height & 83 & 82 & 80 & 32 & 30 \\
\hline Half-width, $\mathrm{cm}^{-1}$ & 15 & 15 & 16 & 22 & 20 \\
\hline Integrated area & 3034 & 3160 & 3190 & 1730 & 1525 \\
\hline Total area & 4031 & 4354 & 4321 & 4387 & 4156 \\
\hline \multicolumn{6}{|c|}{ Percentage contribution by each band } \\
\hline $2123 \mathrm{~cm}-1$ & 13.4 & 16.2 & 15.5 & 29.5 & 30.5 \\
\hline $2092 \mathrm{~cm}-1$ & 11.3 & 11.2 & 10.7 & 31.0 & 32.8 \\
\hline $2073 \mathrm{~cm}-1$ & 75.3 & 72.6 & 73.8 & 39.5 & 36.7 \\
\hline
\end{tabular}

Gaussian with a peak frequency of 2061 $\mathrm{cm}^{-1}$ was found to be necessary. This peak can be identified with either isolated $\mathrm{CO}$ molecules or $\mathrm{CO}$ adsorbed on low-coordination sites. In a complete cycle, for most of the oxygen portion of the period (length A), the intensities of the 2123- and 2073$\mathrm{cm}^{-1}$ bands are high and there is no 2092$\mathrm{cm}^{-1}$ band. Only one spectrum is given for this region because all of the individual spectra were identical. During this time the $\mathrm{CO}_{2}$ production was below the detection limit of the spectrometer.

Small amounts of $\mathrm{CO}_{2}$ are produced all the time for either $\mathrm{CO}$ or oxygen in the gas phase. After the induction period $\mathrm{A}$, the intensity of the $2073-\mathrm{cm}^{-1}$ band starts decreasing sharply. The intensity of the 2092$\mathrm{cm}^{-1}$ band increases dramatically and a surge in $\mathrm{CO}_{2}$ production occurs at point $\mathrm{e}$ in Fig. 6a. This surge coincides with the maximum in the integrated area of the $2092-\mathrm{cm}^{-1}$ band. After the $\mathrm{CO}$ pulse is on, the inte- grated absorbance of the $2092-\mathrm{cm}^{-1}$ band continues increasing, reaching a maximum roughly halfway through the $\mathrm{CO}$ pulse (point $j$ in Fig. 6a). At this point the 2092$\mathrm{cm}^{-1}$ band has the maximum integrated absorbance and a large surge of gas-phase $\mathrm{CO}_{2}$ is again detected. In comparison the $2073-\mathrm{cm}^{-1}$ band absorbance is almost zero and starts increasing after the $2092-\mathrm{cm}^{-1}$ band starts decreasing. This decrease is accompanied by a sharp drop in the gas-phase $\mathrm{CO}_{2}$ concentration. From the deconvolution results we also observe that, in contrast to transients of the type shown in Fig. 3 , the absorbance of the $2061-\mathrm{cm}^{-1}$ band increases before the $2073-\mathrm{cm}^{-1}$ band.

Figure 7 shows the behavior of gas-phase $\mathrm{CO}_{2}$ and $\mathrm{CO}$ concentration in the immediate vicinity of the catalyst surface during periodic operation under similar conditions but with a monolithic reactor designed to detect fast gas-phase transients (11). Again there is a lag time after oxygen is intro-

\section{TABLE 2}

Results of Gaussian Peak Deconvolution of Selected Individual Spectra during Periodic Operation

\begin{tabular}{|c|c|c|c|c|}
\hline $\begin{array}{c}\text { Location in } \\
\text { Fig. } 6 a\end{array}$ & $\begin{array}{l}\text { Peak frequency, } \\
\mathrm{cm}^{-1}\end{array}$ & Peak height & Half-width & $\begin{array}{c}\text { Integrated } \\
\text { area }\end{array}$ \\
\hline \multirow{4}{*}{ b } & 2123 & 53.6 & 10.6 & 1429 \\
\hline & 2098 & 9.2 & 9.7 & 219 \\
\hline & 2071 & 40.4 & 11.9 & 1203 \\
\hline & 2061 & 18.5 & 32.3 & 1500 \\
\hline \multirow{4}{*}{ d } & 2123 & 53.9 & 10.7 & 1443 \\
\hline & 2098 & 22.9 & 10.4 & 599 \\
\hline & 2071 & 27.7 & 12.9 & 898 \\
\hline & 2060 & 13.1 & 31.5 & 1030 \\
\hline \multirow{4}{*}{ c } & 2123 & 53.1 & 10.6 & 1416 \\
\hline & 2098 & 25.7 & 12.1 & 783 \\
\hline & 2071 & 13.7 & 14.2 & 490 \\
\hline & 2062 & 8.2 & 26.8 & 549 \\
\hline \multirow{4}{*}{ f } & 2123 & 52.8 & 10.6 & 1403 \\
\hline & 2096 & 20.8 & 11.4 & 584 \\
\hline & 2070 & 14.1 & 13.6 & 489 \\
\hline & 2062 & 9.0 & 26.2 & 574 \\
\hline \multirow{4}{*}{$\mathrm{h}$} & 2123 & 52.6 & 10.6 & 1397 \\
\hline & 2098 & 27.5 & 12.9 & 888 \\
\hline & 2067 & 9.8 & 13.4 & 330 \\
\hline & 2062 & 8.2 & 25.4 & 523 \\
\hline \multirow{4}{*}{ j } & 2123 & 48.6 & 10.3 & 1255 \\
\hline & 2086 & 43.9 & 20.5 & 2254 \\
\hline & 2075 & 45.6 & 6.9 & 79 \\
\hline & 2056 & 9.3 & 29.7 & 695 \\
\hline
\end{tabular}



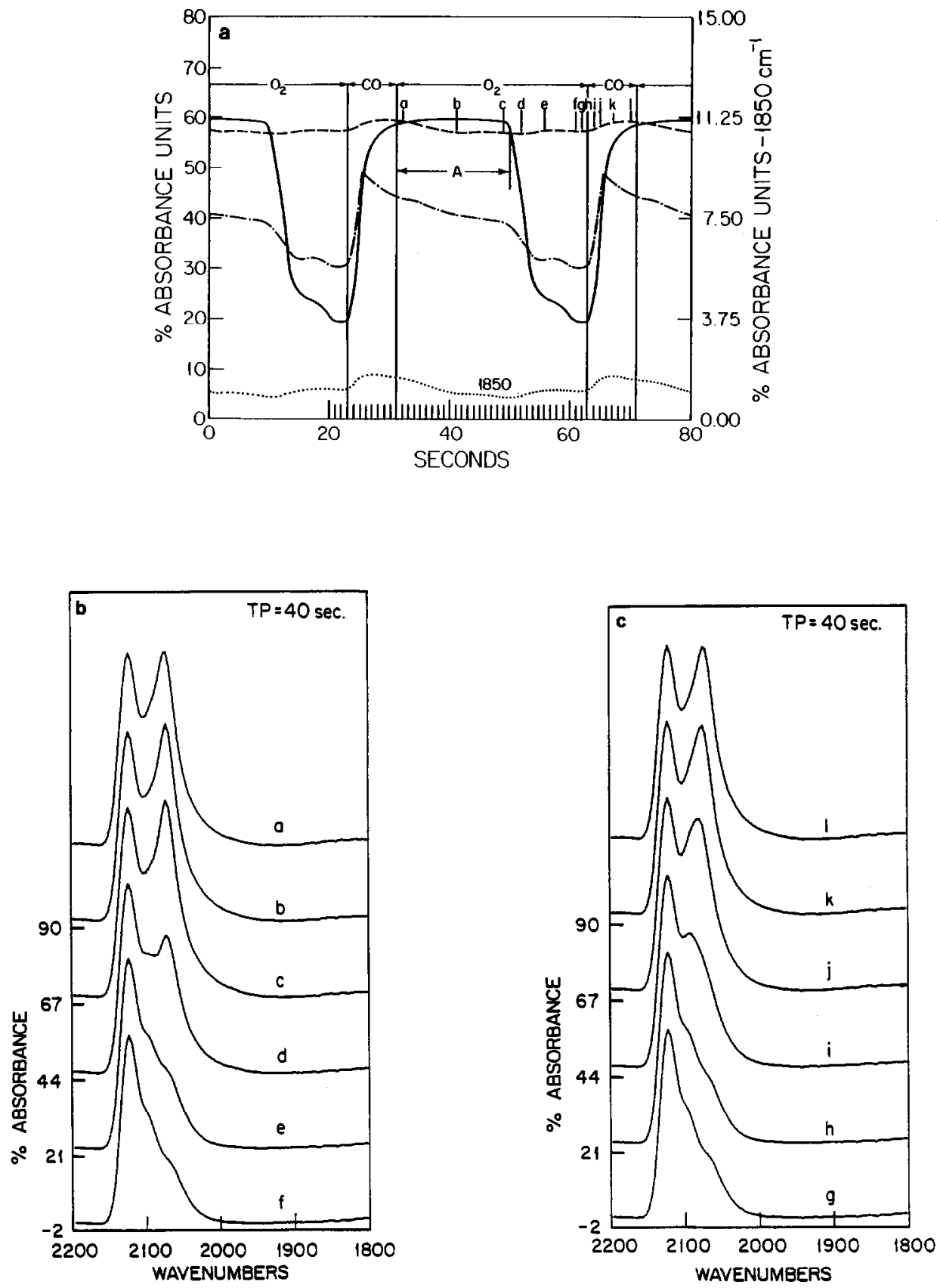

FIG. 6. (a) Plot of time-dependent changes in the peak absorbances of the IR bands during periodic operation with a period of $40 \mathrm{sec}$ and a $\mathrm{CO}$ duty fraction of 0.2 . The continuous curves shown were obtained by joining individual data points (not shown for clarity) separated by 0.6 sec. Also shown are the $\mathrm{CO}$ and $\mathrm{O}_{2}$ portions of the period. Lowercase letters indicate the locations of individual spectra which were analyzed in detail. (-) $2073 \mathrm{~cm}^{-1}$, (--) $2123 \mathrm{~cm}^{-1}$, and (-...) $2092 \mathrm{~cm}^{-1}$. (b) Some of the individual spectra taken during periodic operation. The lowercase letters refer to the corresponding location in (a). (c) Some of the individual spectra taken during periodic operation. The lowercase letters refer to the corresponding location in (a). 
duced and there are two peaks in the $\mathrm{CO}_{2}$ concentration per period.

\section{DISCUSSION}

\section{a. CO Adsorption on Reduced Platinum}

One of the central questions regarding adsorption $\mathrm{CO}$ on platinum group metals has been the question of patch-like adsorption (island formation) or random uniform adsorption. Unfortunately, there is no direct way of determining whether this type of adsorption occurs on polycrystalline catalyst particles, and we must rely on indirect evidence. Crossley and King (12) demonstrated that the frequency shifts observed in the stretching frequency of linearly adsorbed $\mathrm{CO}$ on single-crystal platinum surfaces are entirely due to adsorbate-adsorbate coupling interactions. Transient adsorption results given in Fig. 3a show that the main adsorption band peak frequency is stable for more than an order of magnitude in absorbance (or surface coverage). This can be taken as an indication that the environment for individual $\mathrm{CO}$ molecules adsorbed onto the surface does not change while the total surface coverage increases. One possible reason for the observed behavior is island-like adsorption. In this type of adsorption most of the $\mathrm{CO}$ molecules will be in the inside of the island, thus their stretching frequency will not change as the island size or the number of islands increase. A second possibility, chromatographic adsorption, has been pointed out by Bell and co-workers for palladium (13). While we cannot completely disprove chromatographic adsorption possibility there is strong evidence against it. If chromatographic adsorption is the mode of adsorption the absorbance at the peak should increase linearly with time for a square concentration front advancing through the pellet. Figure $3 \mathrm{~b}$ shows the $\mathrm{ab}-$ sorbance as a function of time at two frequencies. It is clear that linear increase is not the case. The curve for $2076 \mathrm{~cm}^{-1}$ has two characteristic times, a short one of 3 $\mathrm{sec}$, and a much longer one of about $80 \mathrm{sec}$.
A simple calculation using the analytical solution of Dudukovic (14) for a pellet shows that, for our case, the concentration of $\mathrm{CO}$ in the middle of the pellet reaches its value on the outside of the pellet in less than 1 sec. Yet even after almost $100 \mathrm{sec}$ the peak absorbance is only half of the maximum reached after $10 \mathrm{~min}$. A final point to consider is the fact that at $413 \mathrm{~K}$ there is a reasonable amount of desorption of $\mathrm{CO}$ preventing complete chromatographic adsorption. Based on the above evidence we tend to believe in island-like adsorption under the conditions of our experiments. Similar conclusions have been reached by Haaland and Williams (15), and Gonzales et al. (16). The change in the characteristic time shown in Fig. 3b is not surprising because, as suggested by Nishiyama and Wise (17), the activation energy for $\mathrm{CO}$ desorption is coverage dependent. In contrast to Fig. 3a the peak frequency shifts downward significantly when the adsorbed $\mathrm{CO}$ is reacted with hydrogen, as shown in Fig. 2, or during nonreactive thermal desorption. These findings arc again in agrecment with the results of Haaland and Williams (15).

\section{b. Periodic Operation and Rate \\ Enhancements}

One of the more interesting recent findings about catalytic oxidation of $\mathrm{CO}$ over supported platinum has been the enormous rate enhancements obtained by periodic feed switching. Cutlip (6) explained the increased rate as being due to increased surface coverage by oxygen. Critics have also tended to attribute the increase to mass and heat transfer effects during concentration cycling. Our main aim in this study was to find out the reasons for the dramatic rate enhancements and, if possible, the surface species responsible for it. Despite the very large number of publications on the subject, the exact mechanism of $\mathrm{CO}$ oxidation and the surface species taking part in the ratedetermining step are not known. Eladheri and Tsotis (18) observed that the IR absorbance at $2073 \mathrm{~cm}^{-1}$ oscillated out of 
phase with the gas-phase $\mathrm{CO}_{2}$ concentration. Haaland and Williams (15) found no direct correlation between the $\mathrm{CO}_{2}$ production rate and the intensity of any of the $\mathrm{CO}$ bands they were observing (2073 and 1850 $\mathrm{cm}^{-1}$ ). They concluded that a yet undetected surface species was responsible for $\mathrm{CO}_{2}$ production.

We believe that the $\mathrm{CO}$ absorption spectra obtained during periodic operation provides some possible answers to the question of surface species responsible for $\mathrm{CO}_{2}$ production. If, in Fig. 5a, we compare the steady-state spectrum with the periodic operation spectra with $\mathrm{TP} \geq 30 \mathrm{sec}$, we see two dramatic differences: (i) the $2120-\mathrm{cm}^{-1}$ peak is higher during periodic operation and the $2092-\mathrm{cm}^{-1}$ peak is very clearly present during periodic operation but absent during steady state, and (ii) the relative intensity of the $2073-\mathrm{cm}^{-1}$ band is lower. Overall, however, the total integrated absorbances are the same within error limits $( \pm 7 \%)$. In Fig. 5b we have plotted the integrated intensities of the four $\mathrm{CO}$ bands given in Table 2 along with the time-averaged $\mathrm{CO}_{2}$ concentration in the outlet (which is proportional to the time-average rate of reaction). We see that the outlet concentration of $\mathrm{CO}_{2}$ shows a slow increase as the time period is increased from 10 to $20 \mathrm{sec}$ and then a sharp increase in going from TP $=20 \mathrm{sec}$ to $\mathrm{TP}=30 \mathrm{sec}$ (the precise time period for observing this sudden jump is 25 sec). At $30 \mathrm{sec}$, the time-averaged $\mathrm{CO}_{2}$ concentration is exactly three times the steadystate value. If one of the surface $\mathrm{CO}$ species is responsible for the increased rate, then its surface coverage should also change by a parallel amount. Looking at the integrated absorbances of the four $\mathrm{CO}$ stretch bands we see that changes in the integrated absorbances of the 2092- and 2123- $\mathrm{cm}^{-1}$ bands correlate with the changes in the $\mathrm{CO}_{2}$ concentration quite well. For the bands at 2073 and $1850 \mathrm{~cm}^{-1}$ we have negative correlation, in good agreement with Eldaheri and Tsotis (18).

If we make the somewhat questionable assumptions that there is no IR-inactive $\mathrm{CO}$ species on the catalyst surface, and that the extinction coefficients for all the linearly adsorbed $\mathrm{CO}$ species are roughly the same, the total absorbance data given in Table 2 leads to the conclusion that surface coverage by $\mathrm{CO}$ does not change when going from steady state to equivalent periodic operation. Thus the increase must be due to a change in the surface concentration of the active species.

Perhaps the most clear-cut conclusion one can draw from the results of time-averaged IR spectra is that the increased rates of reaction during periodic operation are due to changes occurring on the catalyst surface and not due to heat and mass transfer effects. Based on Fig. 5b it is very difficult to distinguish which $\mathrm{CO}$ species is the active one. If the increase in the rate of reaction is due to an increase in the active surface $\mathrm{CO}$ species then the $\mathrm{CO}$ species absorbing at 2123 and $2092 \mathrm{~cm}^{-1}$ are the candidates. As seen in Fig. 5b, the increases in the areas of these bands, particularly the $2092-\mathrm{cm}^{-1}$ band, closely parallel the changes in the $\mathrm{CO}_{2}$ concentration. A somewhat less plausible argument would be to say that increased rates of reaction would lead to reduced surface concentration of the active $\mathrm{CO}$ species $\left(2073 \mathrm{~cm}^{-1}\right)$.

If we look at Fig. 6a and Table 2 we see that the peak width, absorbance at the peak frequency, and the total integrated absorbance of the $2123-\mathrm{cm}^{-1}$ band are all constant during one complete cycle. Thus it is clear that the $\mathrm{CO}$ adsorbed on platinum oxide is not taking part in the reaction and we are left with three candidates for the active species: $\mathrm{CO}$ adsorbed on a platinum atom sharing an adsorbed oxygen with a neighbor $\left(2092 \mathrm{~cm}^{-1}\right)$, CO adsorbed on metallic platinum (2073 and $2061 \mathrm{~cm}^{-1}$ ), and an IR-inactive $\mathrm{CO}$ species that cannot be detected. Since there is no literature evidence for the existence of significant amounts of IR-inactive $\mathrm{CO}$ on $\mathrm{Pt}$ we will ignore this possibility. All along the time period marked by $A$ in Fig. 6a the spectra show no change, as seen 
from the individual spectra given in Fig. 6b, and very little $\mathrm{CO}_{2}$ is produced. Yet during this time the integrated absorbance due to $\mathrm{CO}$ adsorbed on metallic platinum (2061 and $2073-\mathrm{cm}^{-1}$ peaks) is quite high, accounting for almost two-thirds of the total absorbance as given in Table 2. Thus it is clear that high levels of surface $\mathrm{CO}$ adsorbed on metallic $\mathrm{Pt}$ do not result in high reaction rates.

During one period two large surges in $\mathrm{CO}_{2}$ concentration in the gas phase are seen. The peak of the first surge is at point $e$, and the larger second surge is between points $i$ and $j$ in Fig. 6a. If we look at the individual spectra or Table 2 we see that these are precisely the points at which the integrated absorbance of the $2092-\mathrm{cm}^{-1}$ band is high and the integrated absorbance of the 2073- and 2061- $\mathrm{cm}^{-1}$ bands are low. Particularly at point $\mathrm{j}, \mathrm{CO}$ adsorbed on partially oxidized platinum has the highest absorbance. At point e it is clear that $\mathrm{CO}$ adsorbed on metallic platinum is the source of $\mathrm{CO}$ for both the $\mathrm{CO}_{2}$ produced, and also the $\mathrm{CO}$ adsorbed on partially oxidized platinum. On the other hand at points $i$ and $j$ it is equally clear the $\mathrm{CO}$ adsorbed on partially oxidized platinum comes from gas-phase $\mathrm{CO}$ because there is very little $\mathrm{CO}$ adsorbed on metallic platinum. If we assume that the same mechanism is responsible for the formation of $\mathrm{CO}_{2}$ at all four points we reach the conclusion that at points $i$ and $j$ the observed $\mathrm{CO}_{2}$ is produced from $\mathrm{CO}$ adsorbed on partially oxidized platinum which is the only active species on the surface. Supporting evidence for this is again available from our see-through reactor results shown in Fig. 7. The surge in the gas-phase $\mathrm{CO}_{2}$ concentration during the $\mathrm{O}_{2}$ on portion of the period is significantly lower than the surge during the $\mathrm{CO}$ on portion of the period is in excellent agreement with the integrated absorbances given in Table 2. The level of gas-phase $\mathrm{CO}_{2}$ is also higher between points $\mathrm{e}-\mathrm{h}$ than between points a-c again in agreement with the integrated absorbance of the $2092-\mathrm{cm}^{-1}$ band given in Table 2 . This very

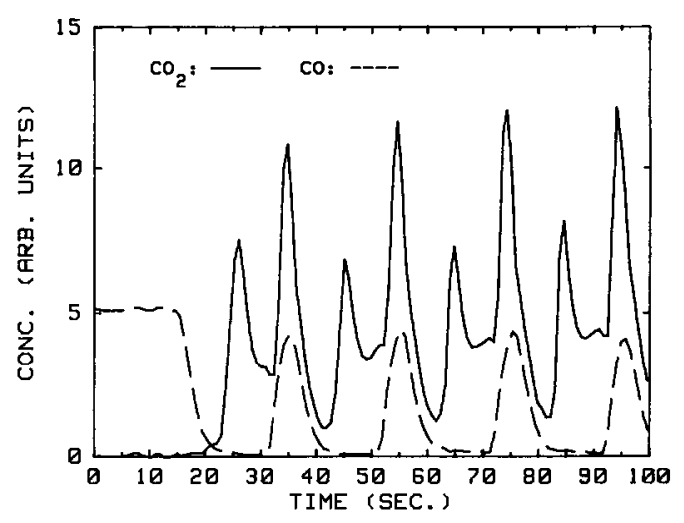

FIG. 7. Gas-phase $\mathrm{CO}$ and $\mathrm{CO}_{2}$ concentrations inside a monolithic honeycomb-supported catalyst during periodic operation. Note that there are two peaks in the $\mathrm{CO}_{2}$ concentration per period.

strong positive correlation between the area of the $2092-\mathrm{cm}^{-1}$ band and the $\mathrm{CO}_{2}$ production rate during periodic operation establishes the surface species responsible for this band as the primary candidate for the reactive intermediate. On the other hand there is no regular correlation with the integrated absorbance of the 2073- $\mathrm{cm}^{-1}$ band.

A final interesting point brought out very clearly by the results in Fig. 6 is the asymmetry of the reaction with respect to gasphasc oxygen and $\mathrm{CO}$. There is an induction time of $19 \mathrm{sec}$ (at $413 \mathrm{~K}$ ) from the time oxygen feed is on to the surge of $\mathrm{CO}_{2}$. In contrast, only $3 \mathrm{sec}$ pass between the time $\mathrm{CO}$ feed is on and the large surge of $\mathrm{CO}_{2}$ seen in the gas phase. We have observed the same asymmetry with palladium (19). In the case of palladium, it is known that $\mathrm{CO}$ islands are formed when oxygen is adsorbed on a $\mathrm{Pd}(111)$ surface with high $\mathrm{CO}$ coverage ( $\phi=0.5$ or higher) whereas the opposite experiment leads to the formation of islands of intimately mixed and reactive $\mathrm{CO}$ and oxygen (20). It is possible that on $\mathrm{Pt}$ the 2092- $\mathrm{cm}^{-1}$ band could be due to a similar surface structure.

Based on the above results, we propose the following model for $\mathrm{CO}$ oxidation during periodic operation: 
(1)

$$
\begin{array}{ll}
\mathrm{O}_{2}+2(\mathrm{Pt})_{n} & \Leftrightarrow \begin{array}{l}
2(\mathrm{Pt})_{n} \mathrm{O}^{*} \\
(\text { relatively slow })
\end{array} \\
\mathrm{O}_{2}+2 \mathrm{Pt} & \Rightarrow 2 \mathrm{PtO} \\
\mathrm{CO}+(\mathrm{Pt})_{n} \mathrm{O}^{*} & \Rightarrow \mathrm{CO}^{*}(\mathrm{Pt})_{n} \mathrm{O}^{*}
\end{array}
$$

(2) $\mathrm{O}_{2}+2 \mathrm{Pt}$

$$
\mathrm{CO}^{*}(\mathrm{Pt})_{n} \mathrm{O}^{*} \quad \Rightarrow(\mathrm{Pt})_{n}+\mathrm{CO}_{2}
$$

$$
\begin{array}{ll}
\mathrm{CO}+\mathrm{Pt} & \Leftrightarrow \mathrm{PtCO}^{*} \\
\mathrm{CO}+2 \mathrm{Pt} & \Leftrightarrow \mathrm{Pt}_{2} \mathrm{CO}^{*} \\
\mathrm{CO}+\mathrm{PtO} & \Leftrightarrow(\mathrm{PtO}) \mathrm{CO}^{*} \\
(\mathrm{PtO}) \mathrm{CO}^{*} & \Rightarrow \mathrm{Pt}+\mathrm{CO}_{2} \\
& \quad(\text { very slow }) \\
\mathrm{PtCO}^{*}+(\mathrm{Pt})_{n} \mathrm{O}^{*} & \Rightarrow \mathrm{CO}^{*}(\mathrm{Pt})_{n+1} \mathrm{O}^{*} \\
\mathrm{CO}^{*}(\mathrm{Pt})_{n+1} \mathrm{O}^{*} & \Rightarrow(\mathrm{Pt})_{n+1}+\mathrm{CO}_{2}
\end{array}
$$

(fast)

Where $n \geq 2$, and the asterisk denotes surface species. The mechanism for the formation of the active species is schematically shown in Fig. 8.

According to this model the reactive oxygens are those that are shared by at least two platinum atoms. As seen in Fig. 6, CO adsorbed on platinum oxide which is easily formed under moderate conditions (21) is inactive in the reaction. A similar observation was made by Herz (22) at higher temperatures. The reaction between the surface oxygen and carbon monoxide occurs when a surface $\mathrm{CO}$ diffuses to the oxygen site (during the oxygen on portion of the period) or when a gas-phase $\mathrm{CO}$ adsorbs on one of the platinum atoms sharing the oxy-

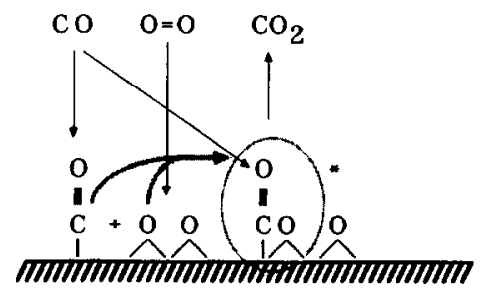

FIG. 8. Schematic diagram showing the structure of the proposed reactive intermediate responsible for $\mathrm{CO}_{2}$ production and the two possible mechanisms leading to its formation during periodic operation. gen. This model satisfies essentially all the necessary requirements:

(i) Adsorption of oxygen during the oxygen on portion of the period is slow because of the need for a multiatom site. Since adsorption is show the concentration of the reactive complex is relatively low. Reactive intermediates are formed by the surface diffusion of $\mathrm{CO}$ to the active oxygen site.

(ii) During the $\mathrm{CO}$ on portion of the cycle the concentration of the reactive intermediate is much higher due to the fact that $\mathrm{CO}$ can adsorb on both metallic and oxygensharing Pt sites. In addition, $\mathrm{CO}$ molecules adsorbed on metallic Pt can diffuse to the active oxygen sites.

(iii) At steady state most of the catalyst surface will be covered with $\mathrm{CO}$ adsorbed on metallic Pt, leaving very few clusters of metallic platinum needed to for active oxygen adsorption sites. Since there is plenty of surface $\mathrm{CO}$ the rate of reaction at steady state will be determined by the availability of the active oxygen sites. The concentration of the reactive intermediate containing both $\mathrm{CO}$ and oxygen will be very low due to the rapid rate of decomposition and the slow rate of formation.

(iv) This model also explains why we were not able to detect significant amounts of the 2092- $\mathrm{cm}^{-1}$ species during an oxygen titration transient of the CO-pretreated catalyst. Since the rate will be limited by step (1) in the mechanism given above, significant amounts of the reactive intermediate cannot accumulate on the surface.

According to the above model the timeaveraged rates of reaction during periodic operation are much higher than the equivalent steady-state rates or the maximum steady-state rates because during periodic operation the surface is never completely covered by adsorbed $\mathrm{CO}$. Exposure to oxygen only, for a large portion of the period, consumes much of the surface $\mathrm{CO}$ and leaves behind a large number of adsorbed reactive oxygen sites which react very rapidly during the $\mathrm{CO}$ portion of the period.

Another observation we have made using 
our see-through reactor (23) provides additional support for the above model: during reactive step testing of the $\mathrm{CO}$-pretreated catalyst with oxygen, some of the adsorbed $\mathrm{CO}$ is seen to desorb and readsorb. This process leads to the formation of multiatom centers for oxygen to adsorb on and always precedes the surge in the $\mathrm{CO}_{2}$ production rate. The induction period seen with oxygen can also be decreased or eliminated completely by purging the reactor with an inert gas for extended periods of time and thus desorbing some of the $\mathrm{CO}$ from the surface.

Finally, we would like to address the issue of temperature excursions during steady state and periodic operation. We monitored the surface temperature of the pellet using an IR thermometer with a spatial resolution of ca. 0.125 in. and thermal resolution of $1 \mathrm{~K}$. No temperature excursions of more than $\pm 2 \mathrm{~K}$ were detectable, and there was no correlation with the changes in the gas-phase concentrations. While not ruling out instantaneous hot spots that can be measured with imbedded thermocouples (23), we conclude that even if under some operating conditions temperature excursions are possible they are not the reason for the increased reaction rates during periodic opcration.

\section{CONCLUSIONS}

The experimental data presented above provide evidence for the following important conclusions:

1. $\mathrm{CO}$ adsorbed on platinum oxide is very stable, nonreactive, and does not diffuse on the catalyst surface. Platinum oxide covered with $\mathrm{CO}$ does not get reduced at an appreciable rate.

2. Under reactive (with oxygen) and nonreactive conditions the frequency of $\mathrm{CO}$ adsorbed linearly on metallic platinum stays constant, providing indirect evidence for adsorption in the form of "islands."

3. The integrated area of the $2092-\mathrm{cm}^{-1}$ band, assigned to $\mathrm{CO}$ linearly adsorbed on platinum atoms sharing an adsorbed oxy- gen with their neighbors, correlates very well with the rate of $\mathrm{CO}_{2}$ production during periodic operation. According to the available evidence this species is the reactive intermediate on the catalyst surface.

4. CO adsorbed linearly on metallic platinum serves as a source of adsorbed $\mathrm{CO}$ when there is no gas-phase $\mathrm{CO}$ but is not the active surface specics.

5. Periodic operation leads to significant changes in the surface concentrations of the various adsorbed $\mathrm{CO}$ species on the surface. During periodic operation the timeaveraged concentration of the reactive intermediate is much higher than steady state leading to dramatically increased rates of reaction.

Based on the experimental evidence a detailed mechanism, which is able to explain all the experimental observations made in this study, is proposed.

\section{ACKNOWLEDGMENTS}

Partial financial support of this research by NSF Grants CPE 8303850, DMR 810130, and ACS-PRF 13210-AC7-C, and Department of Energy Grant DEFG22-84PC70785 is gratefully acknowledged. We would also like to thank Ms. Leslie Matheson for help in preparing the catalyst samples.

\section{REFERENCES}

1. Hugo, P., and Jakubith, M., Chem. Ing. Tech. 44, 383 (1972).

2. Sheintuch, M., and Schmitz, R. A., Catal. Rev. Sci. Eng. 15, 107 (1977).

3. Slinko, M. G., and Slinko, M. M., Catal. Rev. Sci. Eng. 17, 119 (1978).

4. Oh, S. H., Baron, K., Sloan, E. M., and Hegedus, L. L., J. Catal. 59, 272 (1979).

5. Herskowitz, M., and Kenney, C. N., Canad. J. Chem. Eng. 61, 194 (1983).

6. Cutlip, M. B., AIChE J. 25, 502 (1979).

7. Barshad, Y., and Gulari, Erdogan, AIChE J. 31, 649 (1985).

8. Herz, R. K., and Marin, S. P., J. Catal. 65, 281 (1980).

9. Barshad, Y, , PhD thesis. University of Michigan, Mich., 1984.

10. Sheppard, N., and Nguyen, T. T., in "Advances in Infrared and Raman Spectroscopy" (R. G. H. Clark and R. E. Hester, Eds.), Chap. 2, Vol. 5. Hayden, New York, 1976.

I1. Barshad, Y., and Gulari, Erdogan, J. Catal., in press. 
12. Crossley, A., and King, D. A., Surf. Sci. 95, 131 (1980).

13. Hicks, R. F., Yen, Q., and Bell, A. T., J. Catal. 89, 498 (1984).

14. Dudukovic, M. P., Chem. Eng. Sci. 37, 153 (1982).

15. Haaland, D. M., and Williams, F. L., J. Catal. 77, 450 (1982).

16. Sarakany, J., Bartok, M., and Gonzales, R. D., J. Catal. 81, 347 (1983).

17. Nishiyama, Y., and Wise, H., J. Catal. 32, 50 (1974).
18. Tsotsis, T. T., and Eldaheri, A. E., ACS Symp. Ser. 196, 77 (1982).

19. Zhou, X., Barshad, Y., and Gulari, Erdogan, to be published.

20. Engel, T., and Ertl, G., J. Chem. Phys. 69, 1267 (1978).

21. Salmeron, M., Brewer, L., and Somorjai, G. A., Surf. Sci. 112, 207 (1981).

22. Herz, R. K., paper No. 89d, AIChE annual meeting. San Francisco, 1984.

23. Kaul, D. J., and Wolf, E. E., J. Catal. 89, 34 (1984). 